CAROLINA DEL-VALLE-SOTO, Ph.D. ${ }^{1}$

E-mail: cvalle@up.edu.mx

LEONARDO J. VALDIVIA, Ph.D. ${ }^{1}$

(Corresponding author)

E-mail: Ivaldivia@up.edu.mx

RAMIRO VELÁZQUEZ, Ph.D. ${ }^{2}$

E-mail: rvelazquez@up.edu.mx

1 Pan American University, Faculty of Engineering

Álvaro del Portillo 49, Zapopan, Jalisco, 45010, México

2 Pan American University, Faculty of Engineering

Josemaría Escrivá de Balaguer 101, Aguascalientes,

20290, México
Transport Telematics

Preliminary Communication

Submitted: 17 May 2018

Accepted: 4 Apr. 2019

\title{
COMPARISON BETWEEN REACTIVE AND PROACTIVE PROTOCOLS OF WIRELESS SENSOR NETWORKS: RAILWAY APPLICATION
}

\begin{abstract}
Railway is a critical application; hence, all systems that compose the railway infrastructure must meet two conditions: availability and safety. The availability ensures continuous operation of the system; on the other hand, safety is achieved when the device works properly regardless of the environmental or operating conditions. In addition, Wireless Sensor Networks (WSN) are used to perform tasks previously performed manually. However, it is necessary to analyse what protocol is appropriate for the railway industry, since availability and safety are the required attributes. In this work, a recently proposed routing protocol, the Multi-Parent Hierarchical (MPH), has been compared with a well-known protocol, the Ad-hoc On-Demand Distance Vector (AODV), in order to find the most suitable one for the railway applications. For this purpose, a simulator has been developed, which faithfully reifies the workings of a given protocol, considering a fixed, reconfigurable ad-hoc network given by the number and location of participants, and general network conditions.
\end{abstract}

\section{KEY WORDS}

railway; availability; safety; Wireless Sensor Network; routing protocols;

\section{INTRODUCTION}

According to the European Union (EU) in a lapse of seven years (2013 to 2020), about 750 million euro will be invested for research and innovation in the railway sector [1]. Among the activities that the EU wants to promote is the Autonomous Train Operation (ATO) [2]. To achieve this autonomy it is necessary to have smart infrastructure, i.e. infrastructure (bridges, tunnels, tracks, and so on) capable of sending information about its status and thus detect any possible problem that may affect the people's safety. For example, the balises are transmitters placed along the track.
They are used to inform about the maximum speed at which the train can operate, and if this speed is exceeded, the train must brake automatically [3]. One of the causes of the train accident in Santiago de Compostela, Spain where 80 people lost their lives was the lack of balises in the track [4]. Hence, sensors become the key piece in the smart railway infrastructure, since they collect the data that later serve as input to the ATO. For instance, the ATO receives the traffic information and calculates the optimal speed profiles in order to reduce the energy consumption.

The sensors can be wired or wireless. However, the systems based on wired sensors are expensive, not very flexible, require long installation time and the trains have to be stopped during the installation [5]. In this way, the best option is to use a WSN, which transmits all the sensor data to a server for processing.

WSNs differ from other wireless networks, because they are formed by low-cost and low-processing sensors that send information to a collector or base station node [6]. Due to the small size of the nodes in WSNs, the performance metrics is vital as it is very difficult to recharge and aims to achieve maximum efficiency in the delivery of information. Additionally, with a WSN adding or replacing the sensors would be as simple as attaching the sensor (node) to the network, which reduces the installation and maintenance time, saving costs [7].

However, adding a WSN to the railway infrastructure has two main challenges. Firstly, the sensor power consumption should be reduced as much as possible, because of many sensors that are located on not accessible areas, which complicates the battery replacement. Based on the aforementioned aspect, it is necessary to know that the requirements of WSNs are based on nodes that have limited battery power 
and are constrained in energy consumption. The problem of energy use in WSNs is tackled in the utility of such networks in the environments that cannot always allow constant access of humans to change the batteries [8].

The second challenge is the compliance with the safety level required in railway industry, and for this, the WSN must be safe. To ensure safety in the railways, a control system is required. The signalling systems such as the European Train Control System (ETCS) fulfils this purpose. ETCS is a European standard program created to develop a common interoperable platform for railways, authority and signalling systems [9]. The creation of a common control system, ETCS, arises from the need of unifying and ensuring train interoperability regarding the train control and command systems. Therefore, the WSNs must comply with the ETCS requirements in order to implement the sensors on the European trains.

This paper is structured as follows: Firstly, the state of the art describes the safety mechanisms for the systems used in the railway and gives an overview of WSNs for railway industry. Afterwards, the analysis of the scenario in order to make the simulations and the used protocols is detailed. Then, Section 4 describes and explains the performance metrics to be evaluated. Furthermore, Section 5 presents the results. Finally, the conclusion of this research work is presented.

\section{STATE OF THE ART}

This Section is divided into two parts; firstly, the safety mechanisms for the systems used in railway are presented. Secondly, an overview of WSNs and how they are used in railway industry are detailed.

\subsection{Safety mechanisms}

Railway is a safety critical application. Railway in frastructure is based on electronic devices that have replaced systems previously controlled mechanically or manually. As a result, the transportation systems have greater flexibility and maintenance costs have fallen [10]. However, as more electronic systems come into play, it becomes necessary to insure their correct operation.

Thus, to attain the safety in critical systems it is necessary to follow specific standards. The norm that governs the development of a safety critical system is IEC-61508 [11]. It is intended to be the basic functional safety standard applicable to all kinds of industry. However, there are safety norms specifically designed for railways (based on IEC-61508), norms EN-50126 [12], EN-50128 [13] and EN-50129 [14] specify design rules and testing in order to achieve a particular safety specification. Hence, if any manufacturer wants to develop a device for the railway industry it must be certified following these standards.

The railway norms state that a safety critical system needs to tolerate faults and continue to operate normally; hence, errors must not occur and faults should be masked to prevent the occurrence of errors [15]. Norm EN-50129 [14] mentions that redundancy has to be used in order to hide the occurrence of failure from other processes (mask faults).

In redundancy, the same task is or can be performed by multiple devices. Then, if one device stops working the entire system continues working, since other devices perform the tasks of the damaged component.

Therefore, all the railway systems need to be fully and permanently available to perform their function; additionally, redundancy must be used to avoid errors that could lead to accidents.

\subsection{Wireless sensor networks}

A sensor network is composed of nodes that collaborate in a common task. These nodes have certain sensory capabilities and wireless communication that allow routes to change dynamically [16]. In railway industry, the main problems occur due to fading, interference, disconnection of nodes, obstacles, node movements, and so on. In consequence, issues appear, such as quality of service, perishable mobile battery, security, reliability of routes, etc. [17].

In WSN the routing protocols can be classified into two groups: proactive [18] and reactive [19] routing protocols. Proactive protocols are based on tables and determine the routes independently of the traffic model. The neighbouring nodes periodically exchange their complete routing tables with the neighbours to estimate the distance at which the other non-neighbouring nodes are located. The fundamental advantage of proactive protocols is the fact that nodes can easily obtain routing information and establish a session. Among the disadvantages are the existence of a lot of information in the nodes for the maintenance of the routes and that this information is slow to update when there is a failure in some link.

Moreover, hybrid protocols are characterized by providing high integrity in the data link and, at the same time, maintaining a high throughput level of the system. Among different aspects to consider when designing a protocol of these characteristics it must take into account the conditions and requirements of the application. The examples of these protocols are: ZRP [20], SLURP [21], HARF [22], etc. ZRP, for instance, is used in a particular class of ad-hoc networks called Reconfigurable Wireless Networks. These networks are characterized by having a large number of nodes, high mobility and high traffic. ZRP uses zones similar 
to clusters, in which the nodes that act as edges are selected dynamically. In addition, the radius of these zones is readjusted on the fly according to the conditions of the network.

On the other hand, when nodes are under reactive protocol, they ask for a route only when it is needed. When a node wishes to find a path to a destination node, it must initiate a route discovery process. Once the right path is found, it remains until the destination becomes inaccessible or the route is no longer required. This limits the total number of destinations for which the routing information is maintained and therefore the size of the routing tables is reduced. The disadvantages of reactive protocols are the significant latency in the discovery process, the possibility of saturation of the network due to the flooding technique and the lower quality of the routes. This involves high latency for the first packet and some independence among the routes [23].

\subsection{Wireless sensors for railway industry}

In railway industry, the main purpose of using a WSN is for condition monitoring, i.e. multiple sensors are used to verify the condition of the track, bridges, etc. Hence, it helps both to schedule maintenance and notify about any issue that can affect the train integrity [24].

Figure 1 shows a typical WSN for railway industry. It is composed mainly for multiple wireless nodes (sensors) and they send the measures to a central node. Then, this central node is connected directly to a server that saves and processes all the sensor information.

Multiple works analyse the challenges of designing and implementing WSNs in the railway environment [25-29]. However, they do not take into consideration the safety norms that govern the railway industry,

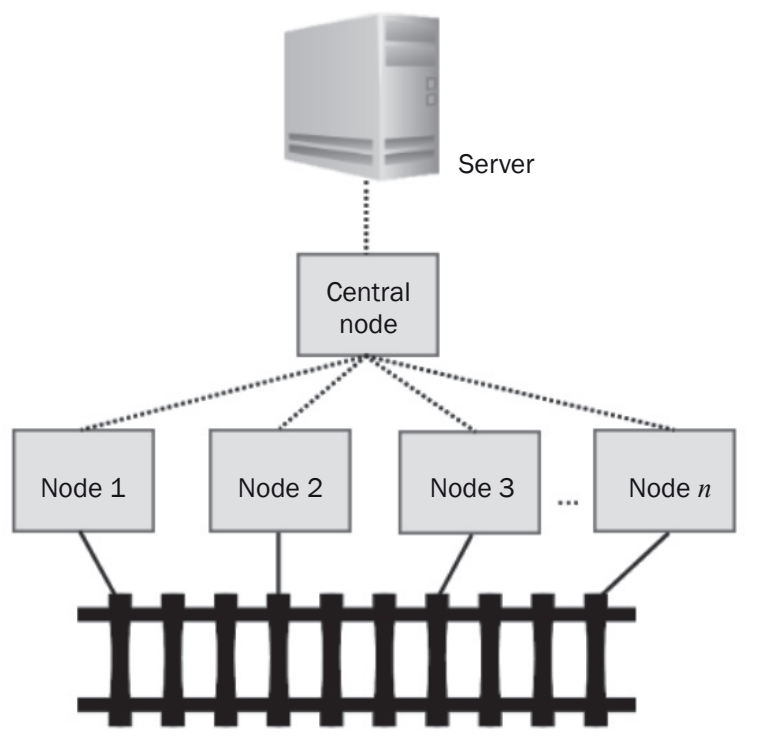

Figure 1 - Typical WSN for railway industry where it is mentioned that special attention must be paid to availability and redundancy to make the WSN fault tolerant.

On the other hand, the main power supply of WSNs are batteries, and of course, all batteries have a finite life. In addition, sensors can be placed on remote and inaccessible locations such as tunnels, bridges, tracks, etc. For this reason, the energy consumption of each network node becomes a critical task. The work [30] shows that using the sleep mode when the sensors are not required can extend the battery life up to 25 times.

Therefore, the most notable issues regarding WSNs are the difficulty in transmitting information in a wireless environment as well as the energy costs implied. The signal fades, obstacles, channel occupancy and interference with other devices motivate the use of powerful mechanisms to send and receive packets successfully. Therefore, the WSN design requires a trade-off between functionality and power consumption, but functionality has to comply with the requirements stated in the safety norms in order to achieve high availability and fault tolerance.

\section{PROPOSED METHODOLOGY}

The aim of this work is to compare two routing protocols to find out which one suits the railway application better than the other. To compare the protocols a test scenario was developed and simulated. Hence, this section is divided into two parts; firstly, the description of the scenario, simulator and the parameters used for the simulation are detailed. Secondly, an explanation of the routing protocols chosen for the comparison is presented.

\subsection{Description of the scenario and simulator}

WSNs have different applications and scenarios. One of the most used network scenario is many-toone, where a collector or central node is in charge of collecting all information captured by sensors and traffic from all sensor nodes is directed to a single sink for processing. This described scenario is the most typical because of the computing capacity, power and storage available on the sensors are very limited. Furthermore, due to reduced storage capacity it is not always feasible to store historical measurements performed by a sensor.

All the network nodes must forward packets to the coordinator node directly (one hop) or indirectly (multiple hops, forming a route with intermediate nodes). It is clear that nodes closer to the coordinator node will carry a larger number of packets than the nodes farther away, and that they will produce an unbalance in the energy depleted in different parts of the network. Our scenario is limited to an environment with static 
nodes, forwarding information to a collector called the coordinator node. This node is the destination node of information.

In this way, different topologies have been developed where each routing protocol form links of nodes and packets are always directed to the coordinator. This node may also request information on any node in the topology. It is a robust node, with more processing power, high-energy consumption and capable of storing large amount of information.

Figure 2 shows a conceptual scheme consisting of 50 nodes distributed along a network 100 metres long and 50 metres wide, with a distribution random uniform. The nodes have a coverage radius between 8 and 10 metres. The scenario used for the simulation is an open field journey (this work does not consider tunnels), the nodes simulate sensors used for track monitoring. These sensors monitor the state of the track, they mainly measure the vibrations, stress and pressures caused by the train [24]. Therefore, multiple types of sensors are required to inform about the state of the railway infrastructure. Additionally, it is important to measure the track conditions in three phases to ensure reliable traffic information. These phases are explained below:

- Before the train passes: the measures taken in this phase are used to know the initial condition of the tracks.

- During train passage: in this phase sensors measure the stress to which the tracks are subjected.

- After the train has passed: the mechanical consequences due to the passage of the train are measured in this stage. All the measures taken in the different stages are compared in order to apply predictive maintenance.

Moreover, the simulation conditions were executed in a simulator programmed in $\mathrm{C}++$, which has already been experimentally tested in another work [31]. The simulator, based on the events, consists of parameters of physical layer, MAC layer and network layer. The energy model is implemented in the functions of the simulator and based on the CC2530 sensor from Texas Instruments [32]. All nodes along the network carry traffic information to a single node, called the collector node. This node is in charge of receiving all information from the network and, generally, it is more robust and has greater consumption supply than the other peers in the network. This is where, according to the routing protocol, the network will configure its link topology so that all nodes can reach that destination or collector node with any route.

Table 1 - Simulation network parameters

\begin{tabular}{|c|c|}
\hline Parameter & Value \\
\hline \multicolumn{2}{|c|}{ General conditions } \\
\hline Scenario & Static \\
\hline Sensor deployment & Medium-scale networks \\
\hline Communication among nodes & Many-to-one \\
\hline Radio communication & Wireless \\
\hline Communication technique & Multi-hop \\
\hline Sampling period & $100 \mathrm{sec}$ \\
\hline Packet size & 22 Bytes \\
\hline Data rate & $250 \mathrm{kbps}$ \\
\hline Propagation time & $0.000026 \mathrm{sec}$ \\
\hline Transmission time & Packet size/Data rate \\
\hline Process time & $0.002 \mathrm{sec}$ \\
\hline Number of nodes & 50 \\
\hline Maximum hop number & 10 \\
\hline Node coverage range & $8 \mathrm{~m}$ \\
\hline \multicolumn{2}{|c|}{ Physical layer parameters } \\
\hline Sensitivity thresholds & -78 to $-94 \mathrm{dBm}$ \\
\hline Transmission power & $4.5 \mathrm{dBm}$ \\
\hline \multicolumn{2}{|c|}{ MAC layer parameters } \\
\hline $\begin{array}{l}\text { 802.15.4 maximum frame } \\
\text { overhead }\end{array}$ & 25 Bytes \\
\hline $\begin{array}{l}\text { Maximum retransmission } \\
\text { number }\end{array}$ & 3 \\
\hline Maximum retry number & 5 \\
\hline Packet Error Rate & $1 \%$ \\
\hline Average frame length & 22 Bytes \\
\hline MAC protocol & IEEE 802.15.4 \\
\hline MAC layer & CSMA/CA \\
\hline \multicolumn{2}{|c|}{ Network layer parameters } \\
\hline Routing & Hierarchical \\
\hline
\end{tabular}

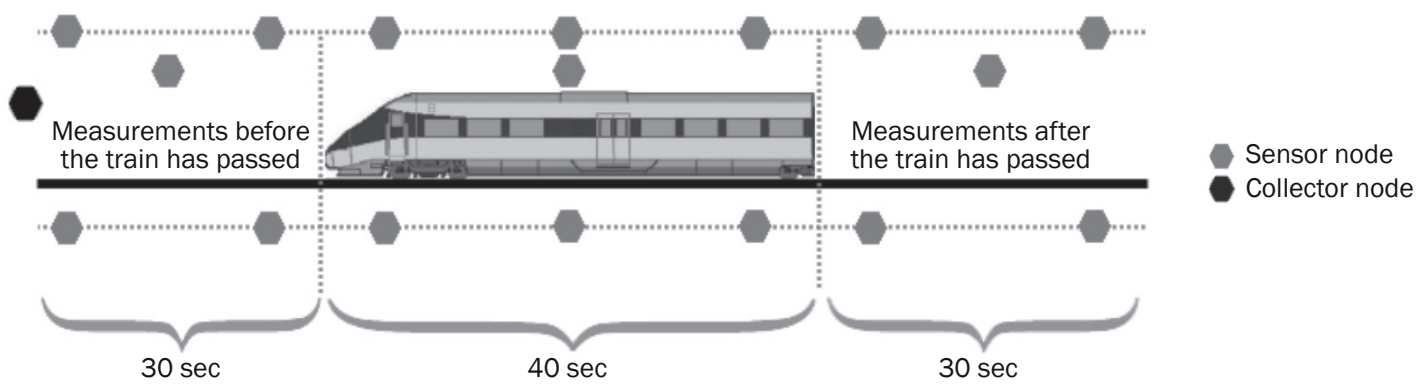

Figure 2 - Scenario under the three stages with respect to the train 
The parameters in Table 1 show the network scenario with respect to general considerations, physical layer parameters, Media Access Control (MAC) layer parameters, and network layer parameters. In the latter, the main characteristic to be implemented is the type of routing protocol that will direct the control of the topology and the network administration packets.

\subsection{Routing protocols}

For this work the Ad-hoc On-Demand Distance Vector (AODV) protocol has been chosen as the representative reactive protocol for the superiority in performance, demonstrated against other reactive protocols reported in the literature [33]. The protocol has been evaluated under the following metrics: packet delivery rate, average delay, routing overload and energy consumption. AODV reduces its performance as the number of nodes increases; consequently, its usability restricts the scalability of the network, additionally, and the results show that the spatial distribution of the nodes influences the performance of the protocol.

Conversely, Multi-Parent Hierarchical (MPH) protocol is chosen as a representative of proactive protocols because it has fast packet delivery characteristics due to its hierarchical nature, and it does not generate too much packet overhead because the periodicity of the route review time is administrable and has a multi-parent characteristic over the links. In addition, this protocol has been tested with several performance metrics for WSNs versus reactive routing protocols and against the Zigbee protocol, which is a fast and efficient protocol. The MPH protocol has presented better performance than the previous ones with respect to efficiency and availability of valid routes, overhead and energy consumption, among other performance characteristics of the network [8].

Additionally, one of the most efficient topologies in information delivery is the hierarchical topology. The hierarchy levels allow packet forwarding with the least number of hops, which causes fewer errors in delivery and lower delays in the transmission of a packet from source to destination [34]. WSNs are multi-functional, low-cost and low-power networks, and rely on communications among nodes or from sensor nodes to one or more sink nodes. Sink nodes, sometimes called coordinator nodes or root nodes, may be more robust and have larger processing capacity than the other nodes [35].

\section{QUALITY PERFORMANCE METRICS}

The metrics of a network layer shows the performance and usefulness of a wireless network. Each network is designed for specific applications and certain scenarios. The availability of effective routes to send information and the ability of the network for self-configuration show the capacity of the network to recover from topology changes. This section explains the parameters selected and used to compare the performance of both reactive and proactive protocols.

\subsection{Availability, redundancy of routes and overhead}

Metrics of the network layer are very important because they show the performance and usefulness of a routing protocol. These metrics indicate how the use of bandwidth is affected by the overhead of the routing protocol in use. In addition, the availability of effective routes and the ability of the network for self-configuration show the capacity of the protocol to recover from topology changes.

Reliable or valid routes are the routes that are active and can be used by nodes to send packets. These routes may expire or may disappear from the tables due to disconnections of neighbour nodes. The most reliable routes will ensure more reliable delivery of information.

Additionally, to ensure the availability and safety (fault tolerance) it is necessary to have redundancy in the network; i.e. if one node stops working, the information can be sent and delivered through another route and consequently, the operation of the entire system is not affected.

However, redundancy can lead to data transfer overhead. If there are multiple routes, it is necessary to send messages continuously in order to maintain them, so that information does not contribute to the general functioning of the system. Accordingly, there must be a balance between the requirements stated in the railway norms and the WSN design, since norm EN-50129 [14] mentions that redundancy has to be used in order to achieve fault tolerance but overhead should be reduced to avoid collisions.

\subsection{Energy model}

The nodes in the WSN use batteries as power source. Hence, their energy consumption should be limited. The problem of energy use in WSNs is tackled in the utility of such networks in the environments that cannot always allow constant access of humans to change the batteries. One aim of this work is to define the important metrics that influence the energy consumption in a WSN.

Table 2 includes the main types of energy of the basic activities that sensors carry out in a common performance in a network. This model is used for the simulation of both protocols (proactive and reactive ones). The types of energy are Microcontroller Energy (E_MC), starting-up energy (E_Starting), shutdown energy (E_Shutdown), CSMA/CA algorithm energy 
Table 2 - Energy model of the main tasks in a wireless network

\begin{tabular}{||l|c||}
\hline \multicolumn{1}{|c|}{ Sensor activity } & Energy (Joules) \\
\hline \hline E_Starting & 0.000288 \\
\hline E_MC & 0.000956 \\
\hline E_CSMA & 0.00778 \\
\hline E_Switching (RX-TX) & 0.000392 \\
\hline E_Switching (TX-RX) & 0.00125 \\
\hline E_RX & 0.0262 \\
\hline E_TX & 0.00426 \\
\hline E_Shutdown & 0.00141 \\
\hline
\end{tabular}

(E_CSMA), switching energy (E_Switching), transmission energy (E_TX) and receiving energy (E_RX). All these energies are expressed in Joules.

\section{RESULTS}

This Section shows the results obtained from the simulation. First, the energy consumption presented in each stage of the analysed scenario is detailed. Then, the comparison of availability, redundancy and overhead between protocols is shown.

\subsection{Redundancy, availability and overhead}

Figure 3 shows three performance metrics: redundancy, availability and overhead. These parameters are studied under the perspective of two types of routing protocols: proactive (MPH) and reactive (AODV). Again, a simulation of 100 seconds is made, in which, in the first 30 seconds the train has not passed; in the next 40 seconds, the train is passing at that moment; and, in the last 30 seconds, the train has passed (see Figure 2).

Moreover, Figure 3 shows that the proactive protocol has $50 \%$ of redundancy of routes against the reactive protocol. However, the fact that there are many routes to a destination does not always mean that this is a positive aspect. When the network has several routes it is also necessary to maintain them, so this generates overhead, which is why the proactive protocol presents $4 \%$ less overhead than the reactive one.

With respect to the availability of routes, the proactive protocol presents around $12 \%$ of more routes available than the reactive protocol. This may be because the periodic revision of routes keeps them valid most of the time, while in the reactive protocol, the routes generate an error packet when their lifetime expires or when a link is broken, and this generates more overhead.

In this way, under a proactive protocol, the network does not have much redundancy, but it does guarantee reliable routes and this generates less overhead thanks to the maintenance of fewer routes. Therefore, there will be fewer collisions and packet retransmissions and traffic information will be delivered.

\subsection{Energy consumption of the wireless network}

Figure 4 describes the energy performance of the network according to each type of protocol (proactive or reactive) in each of the simulation stages. In the first 30 seconds, the train has not passed yet; the next 40 seconds, the train is passing and it appears as an obstacle in the network and it is here where notorious interference characteristics are observed; finally, the
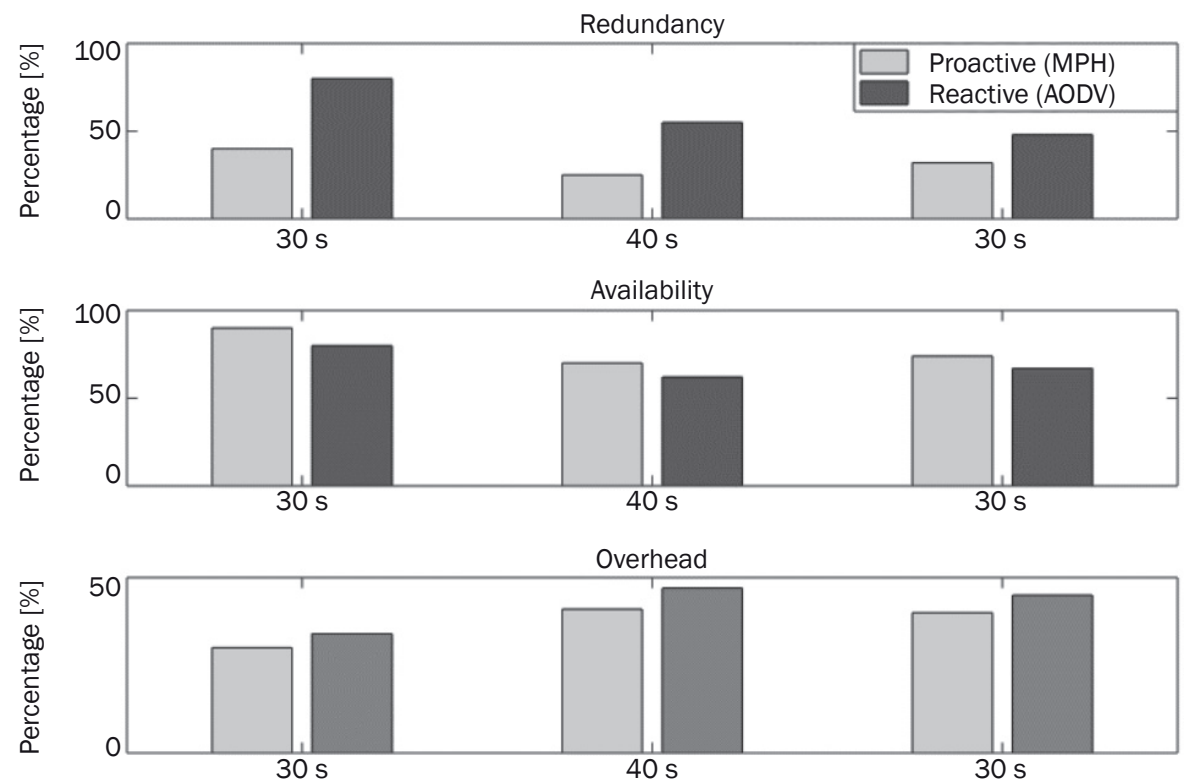

Figure 3 - Performance metrics under the three stages with respect to the train 


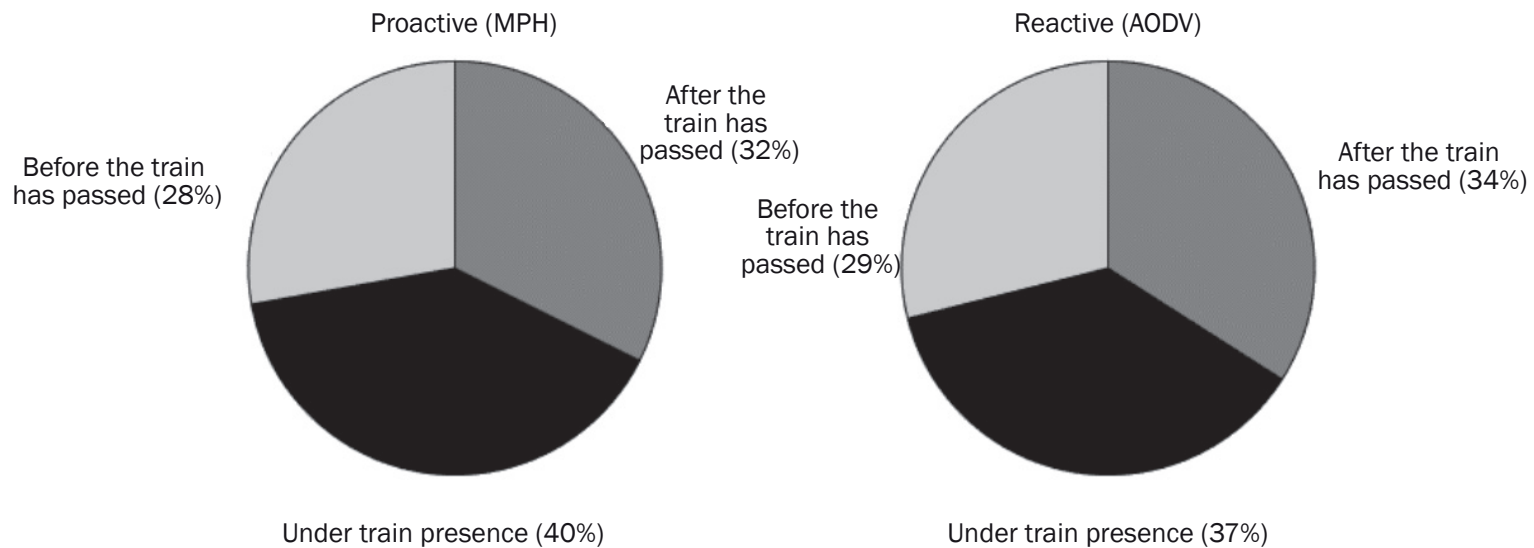

Figure 4 - Energy in percentages under the three stages with respect to the train

Table 3 - Energy in Joules under the three stages with respect to the train

\begin{tabular}{||l|c|c|c||}
\hline \multicolumn{1}{|c|}{ Protocol } & Energy before the train [J] & Energy under train presence [J] & Energy after the train [J] \\
\hline \hline Proactive & 52.2 & 74.8 & 60.8 \\
\hline Reactive & 63.3 & 81.1 & 74.5 \\
\hline
\end{tabular}

last 30 seconds, the train has already passed and the behaviour of the network is observed. With this, 100 seconds of simulation and observation of parameters are analysed. It is very clear that, with a proactive protocol, the difference between the consumption of the network when the train is not passing and the consumption when the train is passing is notoriously higher by $3 \%$ compared to the difference under a reactive protocol.

Moreover, it is easier to detect a specific anomaly in a network under a proactive protocol, because the focus is on the point of the presence of the train with greater intensity of energy consumption. However, this does not mean that a network under this type of protocol has a higher energy consumption; this is shown in Table 3.

Therefore, it is possible to state that the energy consumption of the proactive protocol has greater changes compared to the reactive protocol in the presence of the train. However, the energy consumption of the proactive protocol is always less than the reactive, regardless of the stage analysed (see Table 3).

\section{CONCLUSION}

Safety standards indicate that the critical systems used in the railway applications must have high availability and be fault tolerant. These requirements also apply to WSNs, since any error in data transmission can cause the train to enter the safe mode, and depending on the error, the control system can stop the train to avoid accidents. Therefore, this paper analyses two routing protocols in order to find the most suitable one for railway applications.
Moreover, there must be a balance between the safety norms requirements and the functionality of the wireless network, as some requirements can add problems to WSN, e.g. redundancy can increase data overhead. For this reason, this work simulates the behaviour of the two routing protocols in different stages of a railway journey.

With the information obtained from the simulation, it is possible to affirm that by using proactive protocols, the nodes can obtain the routing information and establish a connection in a simple manner. This allows overhead to be controlled by varying the periodicity of route maintenance.

Thanks to the multi-parent feature in a proactive protocol, redundancy is achieved. Additionally, it takes advantage of the simplicity of the link hierarchy and fast packet delivery to a destination node. By having redundancy, the network is considered fault tolerant; if any fault occurs in a node the information can be delivered by another route, and then errors do not occur, increasing the safety level.

Reactive protocols have a significant latency in the discovery process, the possibility of saturation of the network due to flooding and lower quality and availability of routes. Railway safety standards mention high availability as a must in any critical railway application. This is why a proactive protocol has been proposed with hierarchical characteristics of multi-parent nodes for a train application network. This type of configuration (made thanks to the routing protocol) maintains redundancy, reduces load of control packets, reveals availability of valid and active routes, and reduces energy consumption against a network under a reactive protocol. 


\section{Dr. CAROLINA DEL-VALLE-SOTO ${ }^{1}$}

E-mail: cvalle@up.edu.mx

Dr. LEONARDO J. VALDIVIA ${ }^{1}$

E-mail: Ivaldivia@up.edu.mx

Dr. RAMIRO VELÁZQUEZ ${ }^{2}$

E-mail: rvelazquez@up.edu.mx

${ }^{1}$ Universidad Panamericana, Facultad de Ingeniería Álvaro del Portillo 49, Zapopan, Jalisco, 45010, México

2 Universidad Panamericana, Facultad de Ingeniería Josemaría Escrivá de Balaguer 101, Aguascalientes, 20290, México

\section{COMPARACIÓN ENTRE PROTOCOLOS REACTIVOS Y PROACTIVOS EN REDES DE SENSORES INALÁMBRICOS: APLICACIÓN FERROVIARIA}

\section{RESUMEN}

Los trenes son una aplicación crítica; Por lo tanto, todos los sistemas que componen la infraestructura ferroviaria deben cumplir dos condiciones: disponibilidad y seguridad. La disponibilidad asegura el funcionamiento continuo del sistema; por otro lado, la seguridad se logra cuando el dispositivo funciona correctamente, independientemente de las condiciones ambientales o de funcionamiento. Además, las redes de sensores inalámbricos se utilizan para realizar tareas que previamente se realizaron manualmente. Sin embargo, es necesario analizar qué protocolo es apropiado para la industria ferroviaria, ya que la disponibilidad y la seguridad son atributos obligatorios. En este trabajo, comparamos un protocolo de enrutamiento propuesto recientemente, el Multi-Parent Hierarchical (MPH), con un protocolo bien conocido, el Ad-hoc On-Demand Distance Vector (AODV), para encontrar el más adecuado para aplicaciones ferroviarias. Para lograr esto, hemos desarrollado un simulador, que reproduce fielmente el funcionamiento de un protocolo dado, considerando una red ad-hoc fija y reconfigurable dada por el número y la ubicación de los participantes, y las condiciones generales de la red.

\section{PALABRAS CLAVE}

Ferrocarril; Disponibilidad; Seguridad; Red de sensores inalámbricos; Protocolos de enrutamiento,

\section{REFERENCES}

[1] European Commission. HORIZON 2020 [Internet]. 2014 [cited 2018 Apr 24]. Available from: https://ec. europa.eu/programmes/horizon2020/

[2] European Union. Shift2Rail Innovation Programme 5 [Internet]. 2016 [cited 2018 Apr 25]. Available from: https://shift2rail.org/research-development/ip5/

[3] Beijing Jiaoda Signal Technology Co. BTM-Balise Transmission Module [Internet]. 2016 [cited 2015 Jun 5]. Available from: http://www.jd-signal.com/en/plus/ view.php?aid=19

[4] BBC News. Spain train crash: What happened. 2013; Available from: https://www.bbc.com/news/world-europe-23449336

[5] Kruger M, Grosse C, Kurz J. Sustainable Bridges 5.5. Technical Report on Wireless Sensor Networks using MEMS for Acoustic Emission Analysis including other
Monitoring Tasks. Stuttgart, Germany; 2007.

[6] Guangiie H, Liu L, Jiang J, Shu L, Hancke G. Analysis of Energy-Efficient Connected Target Coverage Algorithms for Industrial Wireless Sensor Networks. IEEE Trans Ind Informatics. 2017;13(1): 135-43.

[7] Bennett PJ, Soga K, Wassell IJ, Fidler P, Abe K, Kobayashi $Y$, et al. Wireless sensor networks for underground railway applications: case studies in Prague and London. Smart Struct Syst [Internet]. 2010;6(5-6): 619-39. Available from: http://koreascience.or.kr/journal/view. jsp?kj=KJKHFZ\&py=2010\&vnc=v6n5_6\&sp=619

[8] Del-Valle-Soto C, Mex-Perera C, Orozco-Lugo A, Lara M, Galván-Tejada GM, Olmedo O. On the MAC/Network/ Energy performance evaluation of wireless sensor networks: Contrasting MPH, AODV, DSR and ZTR routing protocols. Sensors. 2014;14(12): 22811-47.

[9] Rail Safety and Standards Board Limited. GE/GN8605 ETCS System Description; 2010.

[10] Moreu F, Kim RE, Spencer BF. Railroad bridge monitoring using wireless smart sensors. Struct Control Heal Monit. 2017;24(2).

[11] CENELEC. EN61508, Functional safety of electrical/ electronic/programmable electronic safety-related systems. Part 2: Requirements for electrical/electronic/programmable electronic safety-related systems; 2000.

[12] CENELEC. EN50126, Railway applications. The specification and demonstration of Reliability, Availability, Maintainability and Safety (RAMS); 2010.

[13] CENELEC. EN50128, Railway applications. Communication, signalling and processing systems - Software for railway control and protection systems; 2012.

[14] CENELEC. EN50129, Railway applications. Communication, signalling and processing systems. Safety related electronic systems for signalling; 2005.

[15] Rezaee M, Sedaghat Y, Khosravi-Farmad M. A confidence-based software voter for safety-critical systems. Proceedings of the IEEE $12^{\text {th }}$ International Conference on Dependable, Autonomic and Secure Computing, DASC 2014, 24-27 Aug 2014, Dalian, China; 2014. p. 196-201.

[16] Biswas S, Das R, Chatterjee P. Energy-Efficient Connected Target Coverage in Multi-hop Wireless Sensor Networks. Ind Interact Innov Sci Eng Technol [Internet]. 2018;11: 411-21. Available from: http://link. springer.com/10.1007/978-981-10-3953-9

[17] Mainwaring A, Culler D, Polastre J, Szewczyk R, Anderson J. Wireless sensor networks for habitat monitoring. Proceedings of the $1^{\text {st }}$ ACM International Workshop on Wireless Sensor Networks and Applications, WSNA '02, 28 Sep 2002, Atlanta, Georgia, USA; 2002. p. 88-97. Available from: http://portal.acm.org/citation. cfm?doid=570738.570751

[18] Mohemed RE, Saleh Al, Abdelrazzak M, Samra AS. Energy-efficient routing protocols for solving energy hole problem in wireless sensor networks. Comput Networks. 2017;114: 51-66.

[19] Aranzazu-Suescun C, Cardei M. Reactive Routing Protocol for Event Reporting in Mobile-Sink Wireless Sensor Networks. Proceedings of the $13^{\text {th }}$ ACM Symposium on QoS and Security for Wireless and Mobile Networks, Q2SWinet '17, 21-25 Nov 2017, Miami, Florida, USA; 2017. p. 43-50. 
[20] Lv X, Le X, Ding K. An Improved Cluster Routing Algorithm Based on ZRP Protocol. In: Li C, Mao S. (Eds) Wireless Internet. WiCON 2017. Lecture Notes of the Institute for Computer Sciences, Social Informatics and Telecommunications Engineering, vol 230. Springer, Cham; 2018. p. 261-71.

[21] Raheja K, Maakar SK. A Survey on Different Hybrid Routing Protocols of MANET. Int J Comput Sci Inf Technol. 2014;3(5): 5512-6.

[22] Young-Jae K, Young-Joo S. An Efficient Rate Switching Scheme for IEEE 802.11 Wireless LANs. Proceedings of the 2005 IEEE 61 $1^{\text {st }}$ Vehicular Technology Conference Vehicular Technology Conference, 30 May - 1 June 2005, Stockholm, Sweden. IEEE; 2005. p. 2364-8.

[23] Taneja K, Taneja H, Kumar R. Multi-channel medium access control protocols: Review and comparison. J Inf Optim Sci. 2017;39(1): 239-47.

[24] Hodge VJ, Keefe SO, Weeks M, Moulds A. Wireless Sensor Networks for Condition Monitoring in the Railway Industry: A Survey. IEEE Trans Intell Transp Syst. 2015;16(3): 1088-106.

[25] Tolani M, Sunny, Singh RK, Shubham K, Kumar R. Two-Layer Optimized Railway Monitoring System Using Wi-Fi and ZigBee Interfaced Wireless Sensor Network. IEEE Sens J. 2017;17(7): 2241-8.

[26] Wu Y, Jiang B, Lu N, Yang H, Zhou Y. Multiple incipient sensor faults diagnosis with application to high-speed railway traction devices. ISA Trans [Internet]. 2017;67: 183-92. Available from: http://dx.doi.org/10.1016/j. isatra.2016.12.001

[27] Ashiya K. Earthquake Alarm Systems. J Japan Assoc Earthq Eng. 2004;4(3): 112-7.

[28] Ai B, Cheng X, Kurner T, Zhong ZD, Guan K, He RS, et al. Challenges toward wireless communications for high-speed railway. IEEE Trans Intell Transp Syst.
2014;15(5): 2143-58.

[29] Hernandez A, Valdovinos A, Perez-Diaz-de-Cerio D, Valenzuela JL. Bluetooth low energy sensor networks for railway applications. 2017 IEEE Sensors Conference, 29 Oct - 1 Nov 2017, Glasgow, UK [Internet]; 2017. p. 1-3. Available from: http://ieeexplore.ieee. org/document/8234163/

[30] Chebrolu K, Raman B, Mishra N. Brimon: a sensor network system for railway bridge monitoring. Proc $6^{\text {th }}$ Int Conf Mob Syst Appl Serv, MobiSys '08, 17-20 June 2008, Breckenridge, CO, USA [Internet]; 2008. p. 2-14. Available from: http://dl.acm.org/citation. $\mathrm{cfm}$ ?id=1378603

[31] Del-Valle-Soto C, Mex-Perera C, Orozco-Lugo A, Galvan-Tejada GM, Olmedo O, Lara M. An efficient Multi-Parent Hierarchical routing protocol for WSNs. 2014 Wirel Telecommun Symp, 9-11 Apr 2014, Washington, DC, USA; 2014.

[32] Texas Instruments. CC2530 datasheet (Rev. B) [Internet]; 2015. Available from: http://www.ti.com.cn/cn/ lit/ds/symlink/CC2530.pdf

[33] Anwar NB, Chowdhury S, Haque UM, Khan SNMS. Wildlife Monitoring using AODV Routing Protocol in Wireless Sensor Network. Int J Comput Networks Commun Secur. 2018;6(1): 17-23.

[34] Ding G, Sahinoglu Z, Orlik P, Jinyun Z, Bhargava B. Tree-Based Data Broadcast in IEEE 802.15.4 and ZigBee Networks. IEEE Trans Mob Comput. 2006;5(11): 1561-74.

[35] Sarwar MS, Chatterjee P. Optimal Sink Placement in Wireless Sensor Networks to Increase Network Performance. Ind Interact Innov Sci Eng Technol [Internet]. 2018; 11: 423-434. Available from: http://link.springer.com/10.1007/978-981-10-3953-9 